\title{
Graphene-based quasi-solid-state lithium-oxygen batteries with high energy efficiency and a long cycling lifetime
}

\author{
Gang Huang ${ }^{1}$, Jiuhui Han', Chuchu Yang $\mathbb{D}^{1}$, Ziqian Wang${ }^{2}$, Takeshi Fujita $\mathbb{B}^{1}$, Akihiko Hirata ${ }^{1}$ and Mingwei Chen ${ }^{1,2,3}$
}

\begin{abstract}
An aprotic lithium-oxygen battery with an ultrahigh theoretical energy density has attracted significant attention as the next-generation electrochemical energy device demanded by all-electric vehicles and other high-energy devices. Extensive effort has recently been devoted to improving the performances of cathodes, anodes, and electrolytes. However, as an integrated system, the overall battery properties are not determined by the individual components but by the synergy of all components. Despite important progress in the development of cathodes, anodes, and electrolytes, the system-level design and assembly of lithium-oxygen batteries have not benefited from these recent advances. Here, we report a graphene-based quasi-solid-state lithium-oxygen battery consisting of a rationally designed 3D porous graphene cathode, redox mediator-modified gel polymer electrolyte, and porous graphene/Li anode. This integrated prototype battery simultaneously addresses the major challenges of lithium-oxygen batteries and achieves stable cycling at a large capacity, low charge overpotential and high rate in both coin-type and largescale pouch-type batteries. For the first time, these lithium-oxygen batteries as a whole device deliver gravimetric and volumetric energy densities higher than those of a commercial Li-ion polymer battery. This study represents important progress toward the practical implementation of full-performance lithium-oxygen batteries.
\end{abstract}

\section{Introduction}

A nonaqueous rechargeable $\mathrm{Li}-\mathrm{O}_{2}$ battery with a high theoretical specific energy of $3500 \mathrm{Wh} / \mathrm{kg}$ based on the reversible redox reaction $2 \mathrm{Li}+\mathrm{O}_{2} \rightleftharpoons \mathrm{Li}_{2} \mathrm{O}_{2}$ is the only electrochemical energy storage system that can potentially rival the energy level of internal combustion engines ${ }^{1-6}$. A typical aprotic $\mathrm{Li}-\mathrm{O}_{2}$ battery consists of three key components: a porous cathode, a metal $\mathrm{Li}$ anode, and a nonaqueous liquid electrolyte. In the last several years, extensive efforts have been devoted to the improvement of the three major components of the $\mathrm{Li}-\mathrm{O}_{2}$ battery $^{7-13}$. On the basis of the working principle of the aprotic $\mathrm{Li}-\mathrm{O}_{2}$ battery, an ideal $\mathrm{Li}-\mathrm{O}_{2}$ cathode is expected to have open

\footnotetext{
Correspondence: Mingwei Chen (mwchen@jhu.edu)

${ }^{1}$ WPI Advanced Institute for Materials Research, Tohoku University, Sendai 9808577, Japan

${ }^{2}$ Department of Materials Science and Engineering, Johns Hopkins University, Baltimore, MD 21214, USA

Full list of author information is available at the end of the article.

These authors contributed equally: Gang Huang, Jiuhui Han.
}

porosity, high conductivity, good electrochemical stability, and high catalytic activity toward $\mathrm{Li}-\mathrm{O}_{2}$ reactions ${ }^{14,15}$. However, a porous cathode that can concurrently deliver large discharge capacities, high energy efficiency, and a long cycling lifetime needs to be compatible with electrolytes to retain high performance. To overcome the large voltage polarization upon charging, redox mediators (RMs), such as tetrathiafulvalene (TTF), have been successfully employed as charge transfer carriers to enhance oxidation kinetics during charging ${ }^{16-19}$. Nevertheless, the issue that RM molecules shuttle to anodes and oxidize metal $\mathrm{Li}$ must be addressed if RMs are to be used in practical $\mathrm{Li}-\mathrm{O}_{2}$ batteries. In addition, the requirements for large amounts of open space and pore channels for fast mass transport of RMs and accommodation of solid $\mathrm{Li}_{2} \mathrm{O}_{2}$ usually render a large-porosity cathode highly desirable. However, a high-porosity cathode has a low density, which makes large specific capacities of the cathode difficult to translate to an entire device. Unstable solid 
electrolyte interfaces (SEI) and $\mathrm{Li}$ dendrite growth have been long-standing problems with using metal $\mathrm{Li}$ anodes ${ }^{10,11}$. If the Li dendrite issue is not addressed, then the use of metal $\mathrm{Li}$ in a $\mathrm{Li}-\mathrm{O}_{2}$ battery will present serious safety issues. Moreover, in an open $\mathrm{Li}-\mathrm{O}_{2}$ cell system, the exposure of metal Li to oxygen and RMs will cause passivation. Aside from the cathode and anode, the electrochemical stability of electrolytes towards reduced oxygen species is also a problem ${ }^{9,10}$. In addition, the volatile organic liquid-state electrolyte is also problematic in terms of safety. Bearing the above mentioned challenges in mind, the realization of practically promising $\mathrm{Li}-\mathrm{O}_{2}$ batteries requires both the development of highperformance electrode and electrolyte materials and a smart design of entire cells. Graphene is an ideal option for a cathode material owing to its high conductivity, mechanical and chemical stabilities, and large surface $\operatorname{area}^{20,21}$. In particular, the recently developed 3D nanoporous graphene possesses a bicontinuous porous structure with retained high conductivity and large specific surface area of graphene and has been demonstrated to be appealing for $\mathrm{Li}-\mathrm{O}_{2}$ battery cathodes ${ }^{16,21-23}$. However, due to the low mass density $\left(\sim 5-80 \mathrm{mg} / \mathrm{cm}^{3}\right)$ of nanoporous graphene, it accounts for only a very small portion of the weight of the entire cell, and as a result, the high capacity advantage of the porous graphene cathode degrades when the total weight of the battery is considered $^{16}$. For the metal Li electrode, it has been proven that $\mathrm{Li}$ dendrite growth can be efficiently suppressed by increasing the effective surface areas of the $\mathrm{Li}$ electrodes to dissipate the current density for a uniform Li-ion flux ${ }^{11,24}$. This could be realized by embedding Li inside a porous matrix that has high chemical and mechanical stabilities $^{25,26}$. For the electrolytes, a solid-state electrolyte has been gradually recognized as a required option in practical Li- $\mathrm{O}_{2}$ batteries simply due to safety considerations. For instance, a gel polymer electrolyte (GPE) would be able to protect metal $\mathrm{Li}$ anodes from oxygen and inhibit the self-discharge of $\mathrm{RMs}^{27-29}$. Although there has been considerable progress in the development of graphene-based cathodes, dendrite-free $\mathrm{Li}$ anodes, and solid-state electrolytes, the successful integration of these recent advances in one $\mathrm{Li}-\mathrm{O}_{2}$ system for full-performance, practically promising $\mathrm{Li}-\mathrm{O}_{2}$ batteries has not yet been realized. Herein, we report a graphene-based quasi-solidstate rechargeable $\mathrm{Li}_{-} \mathrm{O}_{2}$ battery consisting of a 3D nanoporous graphene cathode, a TTF-modified quasisolid-state GPE (GPE-TTF), and a Li-meal-loaded 3D nanoporous graphene anode. This graphene-based $\mathrm{Li}-\mathrm{O}_{2}$ battery has outstanding performance with stable cycling at large capacities and low charge potentials. In particular, the overall cell gravimetric and volumetric energy densities are appealing for practical applications.

\section{Materials and Methods}

\section{Synthesis of nanoporous grapheme}

The nanoporous graphene was synthesized by a porous, Ni-based chemical vapor deposition (CVD) method $^{21-23}$. Porous Ni dealloyed from NiMn alloy sheets with a thickness of $10 \mu \mathrm{m}$ was employed as the template. To grow nanoporous graphene, the CVD process was conducted at $900^{\circ} \mathrm{C}$ using pyridine as the precursor. Next, the graphenecoated nanoporous Ni substrate was immersed in $2.0 \mathrm{M}$ $\mathrm{HCl}$ solution to etch away the $\mathrm{Ni}$, and free-standing nanoporous graphene film was obtained after supercritical $\mathrm{CO}_{2}$ drying. Thick nanoporous graphene sheets for synthesizing nanoporous graphene/Li anodes and increasing the gravimetric energy density of quasi-solid-state rechargeable $\mathrm{Li}-\mathrm{O}_{2}$ pouch batteries were fabricated by a similar method by using porous $\mathrm{Ni}$ dealloyed from NiMn alloy sheets with thicknesses of 200 and $100 \mu \mathrm{m}$.

\section{Synthesis of the porous graphene/Li anode}

The free-standing nanoporous graphene sheets with a thickness of $\sim 100 \mu \mathrm{m}$ were first transferred to an argonfilled glove box with $\mathrm{O}_{2}$ and $\mathrm{H}_{2} \mathrm{O}$ levels below $0.1 \mathrm{ppm}$ and then placed into Li melt in a stainless steel boat for $20 \mathrm{~s}$, which was heated by a hot plate at $300^{\circ} \mathrm{C}$. The molten $\mathrm{Li}$ was absorbed into the porous graphene sheets through the pores with the color changing from black to silver. The Li loading amount can be tuned by controlling the contact time between the graphene sheet and the molten Li. For example, the 40-s-treated anode has a much higher Li loading than that of the 20-s-treated anode. The proportions of $\mathrm{Li}$ in the porous graphene/Li composites were determined by measuring the maximum Li stripping capacity of the composites and comparing it with the theoretical specific capacity of $\mathrm{Li}$ metal $(3860 \mathrm{mAh} / \mathrm{g})$. Before being loaded into cells, the surfaces of the porous graphene/Li films were smoothed for better electrical contact by slightly pressing the films between two stainless steel plates.

\section{Synthesis of the gel polymer electrolyte}

In total, $0.16 \mathrm{~g}$ fumed silica was uniformly dispersed into $30 \mathrm{ml}$ acetone with the assistance of ultrasonication for $0.5 \mathrm{~h}$. The resultant solution was mixed with $3.84 \mathrm{~g}$ PVDFHFP copolymer and kept still for $12 \mathrm{~h}$ for complete dissolution. Subsequently, this solution was vigorously stirred at $50{ }^{\circ} \mathrm{C}$ for $2 \mathrm{~h}$ and then kept at $50^{\circ} \mathrm{C}$ for one additional hour. The obtained viscous solution was uniformly coated on an aluminum foil sheet with a controlled thickness and cured at $70^{\circ} \mathrm{C}$ in a vacuum overnight. The solidified polymer film was transferred to an argon-filled glove box and soaked in $1 \mathrm{M} \mathrm{LiClO}_{4}$-DMSO electrolyte with and without $50 \mathrm{mM}$ TTF for $24 \mathrm{~h}$. Finally, filter paper was used to wipe away excess liquid electrolyte from the polymer film. 


\section{Materials characterization}

X-ray diffraction (XRD) patterns were collected on a RIGAKU SmartLab 9MTP diffractometer. Raman measurements were carried out by using a Renishaw InVia RM 1000 micro-Raman spectrometer. Scanning electron microscopy (SEM) was performed on a JEOL JIB-4600F field-emission scanning electron microscope. Thermogravimetric (TG) analysis was conducted by using a Thermo plus EVO2 TG-DTA thermogravimetry analyzer from room temperature to $600^{\circ} \mathrm{C}$. X-ray photoelectron spectroscopy (XPS) was collected on an AXIS ultra DLD Shimazu XPS system with an $\mathrm{Al} \mathrm{K \alpha}$ (mono) source in a vacuum of $10^{-7} \mathrm{~Pa}$.

To investigate the discharge products on the nanoporous graphene cathodes at different states, discharged and recharged $\mathrm{Li}-\mathrm{O}_{2}$ coin batteries were disassembled in a glove box. The graphene cathodes were rinsed several times with dimethyl carbonate (DMC). Before XRD measurements, the samples were placed on a glass substrate and sealed by a Kapton polyimide film. The morphological changes in the pure Li foil in a symmetric cell and porous graphene/Li in symmetric and $\mathrm{Li}-\mathrm{O}_{2}$ batteries upon cycling were examined by SEM. The cells were disassembled in a glove box, and the electrodes were washed with DMC and dried in a vacuum.

\section{Electrochemical measurements}

R2032-type symmetric cells were employed to check the cycling stability of the pure $\mathrm{Li}$ and porous graphene/Li anodes. The electrolyte consisted of $1 \mathrm{M} \mathrm{LiPF}_{6}$ dissolved in an ethyl carbonate and diethyl carbonate $(1: 1, \mathrm{w} / \mathrm{w})$ solution. The stripping/plating capacity was $1 \mathrm{mAh} / \mathrm{cm}^{2}$ at a current density of $0.5 \mathrm{~mA} / \mathrm{cm}^{2}$. To measure the Coulombic efficiency, Li/porous graphene or $\mathrm{Li} /$ copper foil cells were assembled, followed by the cycling procedures of depositing $1 \mathrm{mAh} / \mathrm{cm}^{2}$ of $\mathrm{Li}$ onto the porous graphene or copper foil at a current density of $0.5 \mathrm{~mA} / \mathrm{cm}^{2}$ and stripping $\mathrm{Li}$ until the charge potential reached $0.5 \mathrm{~V}$ at the same current density. The electrochemical impedance spectra were collected by a BioLogic VMP3 electrochemical workstation at frequencies ranging from $10 \mathrm{mHz}$ to $100 \mathrm{kHz}$. Linear sweep voltammetry measurements were conducted on a BioLogic VMP3 electrochemical workstation to evaluate the electrochemical window of electrolytes.

R2032-type coin batteries assembled in an argon-filled glove box were used to study the electrochemical performance of $\mathrm{Li}-\mathrm{O}_{2}$ batteries. The free-standing nanoporous graphene cathode and porous graphene/Li anode were separated by GPE or GPE-TTF. Ti mesh was used as the cathode current collector. The quasi-solid-state rechargeable $\mathrm{Li}-\mathrm{O}_{2}$ pouch cell was assembled layer by layer with a porous graphene/Li anode, two pieces of GEP-TTF and two pieces of nanoporous graphene cathodes backed by porous $\mathrm{Al}$ foils and were finally sealed inside an aluminum-laminated film case (Fig. 4a, b). The assembled batteries were then transferred into an Ar-filled chamber and purged with high-purity $\mathrm{O}_{2}$ gas before electrochemical testing. Galvanostatic discharge/charge tests were performed on a Hokuto discharging/charging system at room temperature. All the current densities and specific capacities were calculated on the basis of the mass of graphene cathodes unless otherwise noted.

\section{Results \\ Synthesis and properties of the graphene cathode, GPE- TTF, and graphene/Li anode}

Figure 1a schematically presents the structure of the graphene-based quasi-solid-state rechargeable $\mathrm{Li}-\mathrm{O}_{2}$ battery composed of a porous graphene cathode, a GPE containing $0.05 \mathrm{M}$ TTF (GPE-TTF) and a porous graphene/Li metal composite anode. As shown in Fig. 1b, the flexible and free-standing 3D porous graphene cathode has a distinct bicontinuous porous architecture built by seamfree multilayer graphene sheets and interconnected open pore channels (Supplementary Figure 1a). The high electrical conductivity $\left(\sim 1.2 \times 10^{4} \mathrm{~S} / \mathrm{m}\right)$, large specific surface area $\left(700-1000 \mathrm{~m}^{2} / \mathrm{g}\right)$, and ultrahigh porosity ( $>95 \%$ ), verified by our previous studies ${ }^{16,21,22,30}$, make this 3D nanoporous graphene a highly promising cathode material for $\mathrm{Li}-\mathrm{O}_{2}$ batteries.

The porous graphene/Li anode is prepared by placing a porous graphene sheet into $\mathrm{Li}$ melt. As a result of the lithophilic nature of graphene and the capillary forces generated by porosity, the molten $\mathrm{Li}$ penetrates into the entire bicontinuous scaffold in several seconds and uniformly coats the internal surfaces of the tubular graphene sheets (Fig. 1c). The graphene/Li composite inherits the 3D porous structure of the nanoporous graphene matrix. XRD confirms the successful loading of metallic Li in the composite (Supplementary Figure $1 \mathrm{~b}$ ). To assess the Li stripping/plating behaviors of the porous graphene/Li electrode, symmetrical cells are assembled and tested with a fixed capacity of $1 \mathrm{mAh} / \mathrm{cm}^{2}$ at a current density of $0.5 \mathrm{~mA} / \mathrm{cm}^{2}$ (Supplementary Figure 2a). Significantly, the cell manifests stable voltage profiles with very slow increase in voltage hysteresis over 150 cycles, which obviously contrasts with the pure metal Li electrode that has almost 10 times the increase in the voltage hysteresis after 50 cycles. Furthermore, the Coulombic efficiency (CE) (capacity ratio of Li stripping/plating) of the porous graphene-based cell can be stabilized quickly from $60.2 \%$ in the initial several cycles to a value higher than $95 \%$ after 10 cycles and remains stable for 100 cycles. In contrast, the $\mathrm{CE}$ of the $\mathrm{Cu}$ foil-based cell is rather scattered and declines quickly (Supplementary Figure $2 \mathrm{~b})$. These results reveal the excellent reversibility of the porous graphene/Li electrode. The superb property of the 3D porous graphene/Li electrode can be attributed to its 

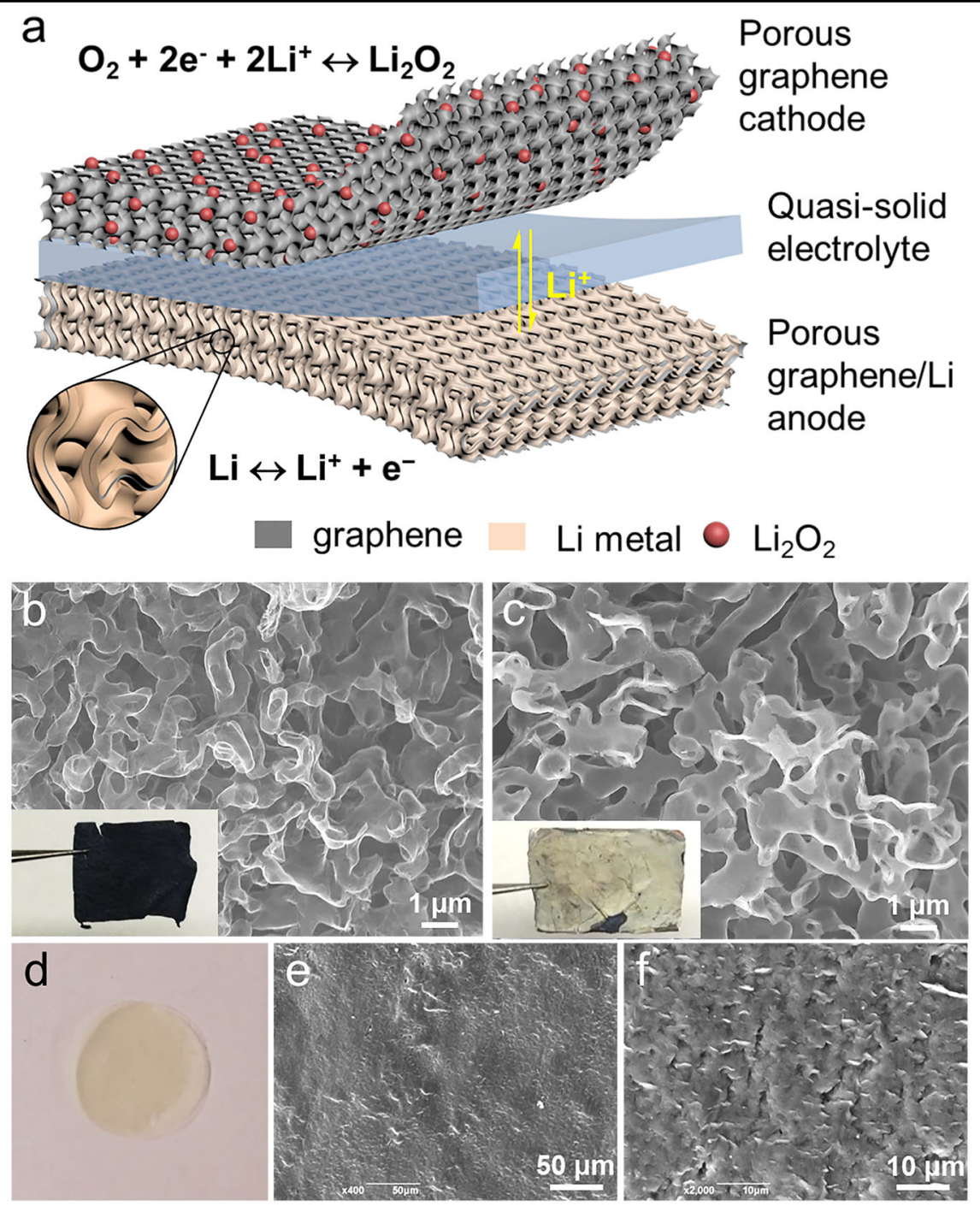

Fig. 1 Configuration and components of quasi-solid-state rechargeable $\mathrm{Li}_{-} \mathrm{O}_{2}$ battery. a Schematic illustration of a quasi-solid-state rechargeable $\mathrm{Li}_{-} \mathrm{O}_{2}$ battery. SEM images of (b) porous graphene cathode and (c) porous graphene/Li anode. Insets show the photographic images. d Optical photograph of GPE-TTF. e, $\mathbf{f}$ SEM images of GPE-TTF with different magnifications

large effective surface area, which enlarges the Li/electrolyte contact interface, decreases the effective current density and reduces the charge transfer resistance (Supplementary Figure 2c). Remarkably, the porous graphene/Li composite can also suppress the formation of Li dendrites. As shown in Supplementary Figure 2d, e, the planar Li metal is fully covered by fibrous Li dendrites after cycling, whereas the graphene/Li composite retains the original porous architecture with a smooth and dendrite-free surface.

An ultrathin quasi-solid-state GPE-TTF electrolyte is fabricated by integrating hemi-crystalline poly(vinylidene fluoride-co-hexafluoropropylene) (PVDF-HFP), nanosized fumed $\mathrm{SiO}_{2}$, and $1 \mathrm{M} \mathrm{LiClO}_{4} / \mathrm{DMSO}$ solution with $50 \mathrm{mM}$ TTF additive (see Experimental section). As shown in Fig. $1 \mathrm{~d}-\mathrm{f}$, the transparent GPE-TTF film is compact and has a thickness of $\sim 10 \mu \mathrm{m}$. The GPE-TTF surface is smooth without the obvious presence of large pores. Although TTF was added initially as a redox mediator to assist the charging reaction of the $\mathrm{Li}-\mathrm{O}_{2}$ battery, it was found that it also enhances the amorphization of GPE as revealed by XRD (Supplementary Figure 3 and Figure 4a), which is expected to boost the ionic conductivity of the solid-state electrolyte ${ }^{31}$. Indeed, electrochemical impedance spectroscopy (EIS) measurements suggest a $\mathrm{Li}^{+}$ion diffusion resistance of $5.1 \Omega$ for GPETTF, lower than the $8.4 \Omega$ for GPE and the $75.4 \Omega$ for a conventional glass fiber separator wetted by liquid electrolyte (glass fiber-LE) (Supplementary Figure 4b). Thermal gravity analysis indicates that GPE-TTF exhibits an elevated DMSO solvent volatilization temperature (Supplementary Figure 4c), demonstrating that GPE-TTF can restrain electrolyte volatilization and has higher thermal 
stability than the glass fiber-LE. The GPE-TTF also exhibits enhanced electrochemical stability, remaining substantially stable at potentials below $4.75 \mathrm{~V}$ (Supplementary Figure $4 \mathrm{~d}$ and Fig. 5). Moreover, the compact GPE-TTF can serve as a protective layer for the metal Li anode to mitigate air-induced $\mathrm{Li}$ passivation (Supplementary Figure 6a, b). Even after 50 cycles, the lithium foil of the GPE-TTF-based $\mathrm{Li}_{-} \mathrm{O}_{2}$ battery remains stable with a metallic luster, while the cycled lithium foil in the $\mathrm{Li}-\mathrm{O}_{2}$ battery using glass fiber-LE loses its metallic luster and becomes partially pulverized (Supplementary Figure 6c). The inhibition of the self-discharge behavior of TTF by GPE-TTF can be demonstrated by permeation tests (Supplementary Figure 7a,c) and electrochemical demonstration (Supplementary Figure 7b, d), revealing the outstanding performance of GPE-TTF in restraining the shuttling of TTF to the anode sides in $\mathrm{Li}-\mathrm{O}_{2}$ batteries. All the advantages mentioned above indicate the highly practical value of GPE-TTF.

\section{Assessment of electrochemical performance in coin cells}

By taking the advantages of a porous graphene cathode, a graphene/Li anode and GPE-TTF, a quasi-solid-state Li$\mathrm{O}_{2}$ coin cell is constructed with the configuration shown in Fig. 1a. As shown in Fig. 2a-c, galvanostatic discharge- charge tests are conducted at cutoff capacities of 500 , 1000 , and $2000 \mathrm{mAh} / \mathrm{g}$ and a current density of $1000 \mathrm{~mA} /$ g, demonstrating the high stability of the quasi-solid-state $\mathrm{Li}-\mathrm{O}_{2}$ battery up to 100 cycles (Supplementary Figure 8a). The discharge potential is $\sim 2.75 \mathrm{~V}$ and the charge potential is as low as $\sim 3.60 \mathrm{~V}$, corresponding to a high energy efficiency of $76 \%$. Moreover, with the increase in cutoff capacities from 500 to $2000 \mathrm{mAh} / \mathrm{g}$, the terminal voltages of both discharge and charge remain nearly unchanged (Supplementary Figure 8a). For comparison, the cycling performance of a pure GPE-based $\mathrm{Li}_{-} \mathrm{O}_{2}$ battery is also tested. As indicated in Supplementary Figure $8 \mathrm{~b}$, c, the cell with GPE exhibits a consistently higher charge overpotential $(\sim 1.65 \mathrm{~V})$ than that of the GPE-TTFbased cell at each discharging/charging cycle, indicating the effectiveness of the introduction of TTF in reducing the charge overpotential. The rate performance shows that the quasi-solid-state $\mathrm{Li}-\mathrm{O}_{2}$ battery manifests stable discharge-charge voltage plateaus and mild polarization for current densities ranging from 100 to $1000 \mathrm{~mA} / \mathrm{g}$ (Fig. 2d). The exceptional rate capability of the cell can be attributed to the high conductivity and large surface areas of the porous graphene cathode and graphene/Li anode as well as the high ionic conductivity of the ultrathin GPETTF. As a control experiment, quasi-solid-state $\mathrm{Li}^{-\mathrm{O}_{2}}$
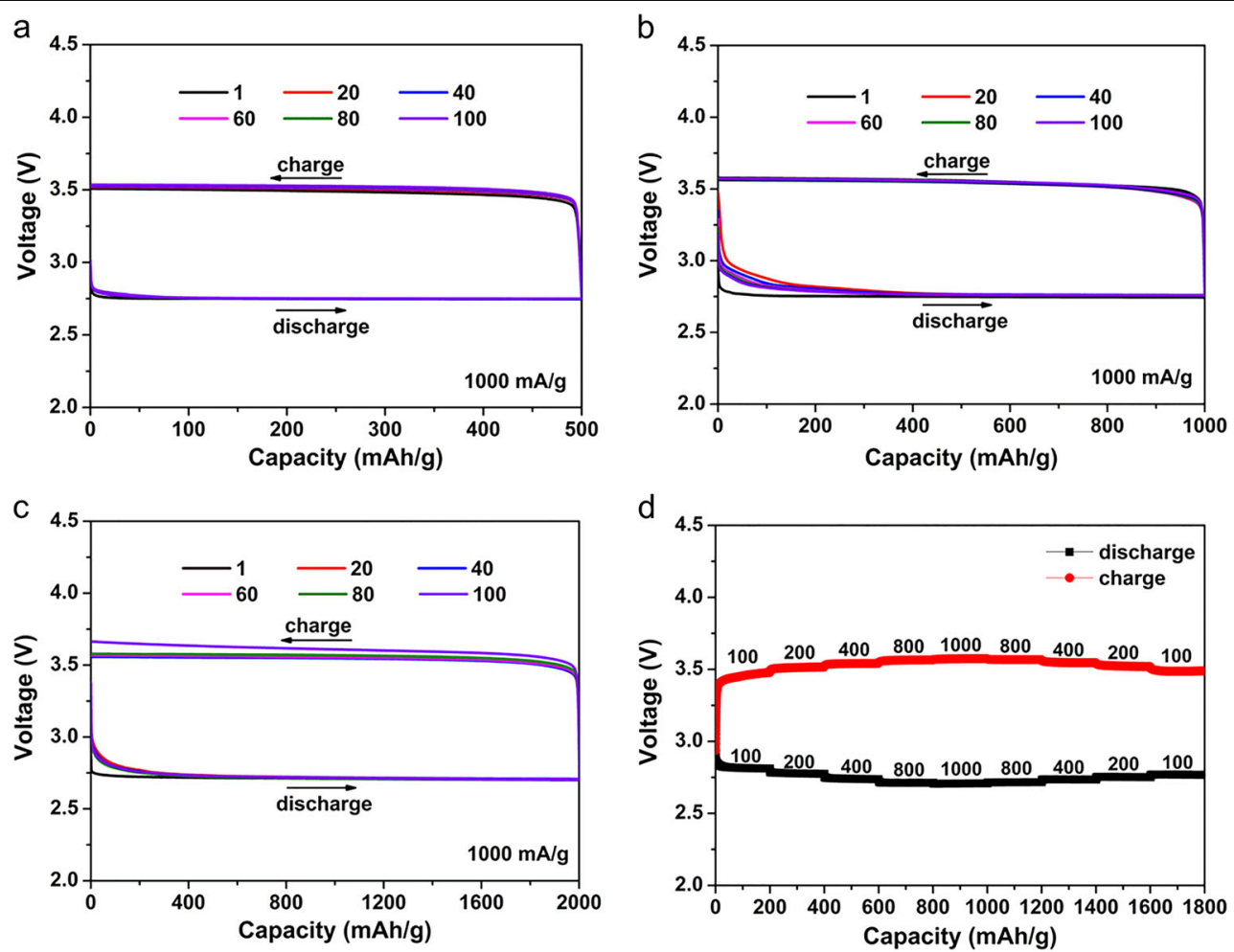

Fig. 2 Electrochemical performance of the quasi-solid-state $\mathrm{Li}_{-} \mathrm{O}_{2}$ coin batteries. Galvanostatic discharge-charge curves of the quasi-solid-state rechargeable $\mathrm{Li}^{-} \mathrm{O}_{2}$ coin batteries with cutoff capacities of (a) $500 \mathrm{mAh} / \mathrm{g}$, (b) $1000 \mathrm{mAh} / \mathrm{g}$, and (c) $2000 \mathrm{mAh} / \mathrm{g}$ at a current density of $1000 \mathrm{~mA} / \mathrm{g}$. d Rate capability of the quasi-solid-state rechargeable $\mathrm{Li}_{-} \mathrm{O}_{2}$ coin batteries 

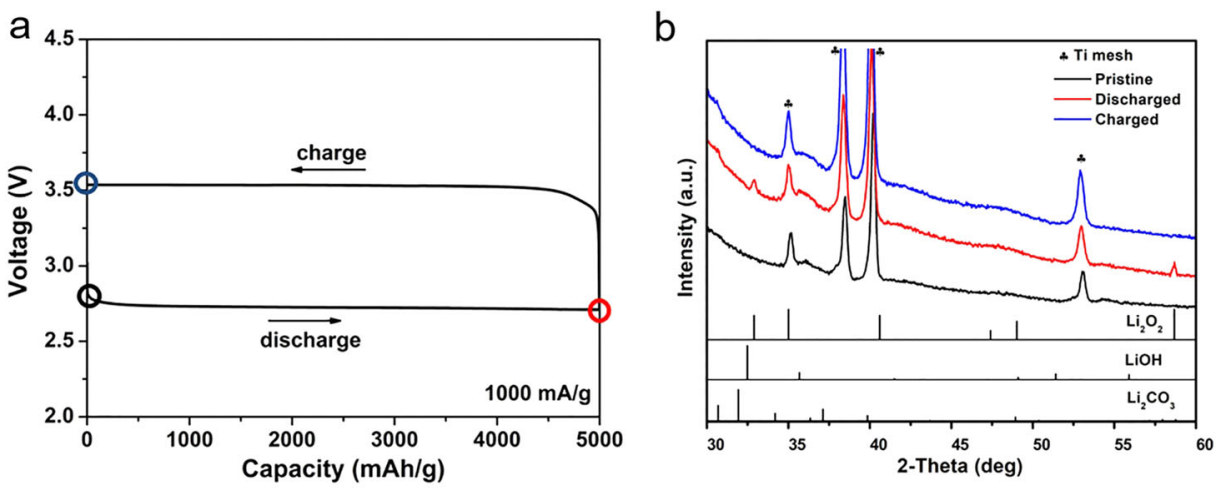

C
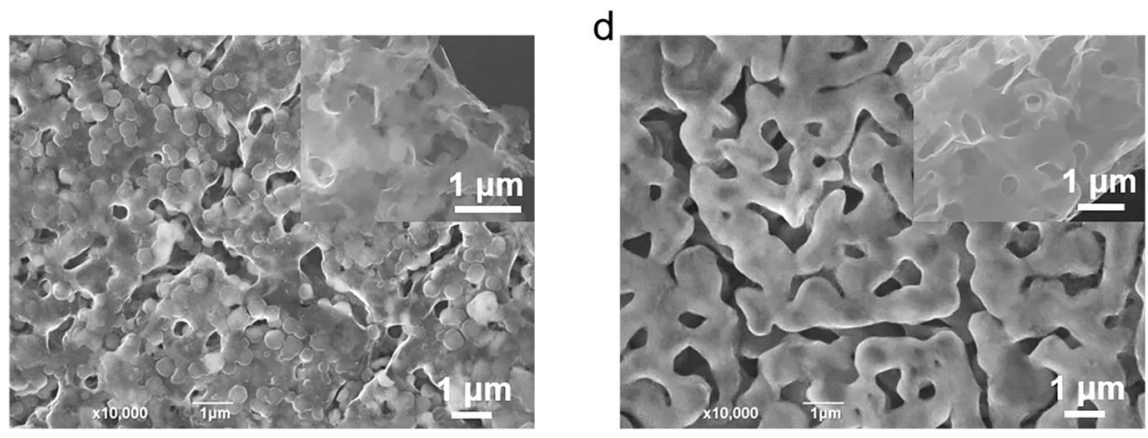

Fig. 3 Characterization of discharge products of the quasi-solid-state rechargeable $\mathrm{Li}_{-} \mathrm{O}_{2}$ battery. a Galvanostatic discharge-charge profiles of the quasi-solid-state rechargeable $\mathrm{Li}_{-} \mathrm{O}_{2}$ coin batteries with a cutoff capacity of $5000 \mathrm{mAh} / \mathrm{g}$ at a current density of $1000 \mathrm{~mA} / \mathrm{g}$. $\mathbf{b}$ XRD patterns of pristine, discharged and recharged porous graphene cathodes. SEM images of (c) discharged and (d) recharged porous graphene cathodes. Insets show cross-sectional SEM images

batteries with a $115 \mu \mathrm{m}$ thick GPE-TTF tested under identical conditions exhibit obvious decline in dischargecharge voltage plateau (Supplementary Figure 8d), demonstrating the critical role of the GPE-TTF film thickness in rate performance. To investigate the impact of the Li loading amount on the cycling performance of $\mathrm{Li}-\mathrm{O}_{2}$ batteries, we prepared a graphene/Li anode with a higher loading amount of Li (82.5 wt.\%, Supplementary Figure $9 \mathrm{~b}, \mathrm{c}$ ) by prolonging the contact time between the graphene sheet and the molten Li from $20 \mathrm{~s}$ to $40 \mathrm{~s}$. Even though a higher loading amount of $\mathrm{Li}$ would enable a higher packing density for the graphene/Li electrode, electrochemical testing shows that increasing the Li proportion from $44.4 \mathrm{wt} . \%$ to $82.5 \mathrm{wt}$ \% does not significantly affect the cycling performance of the quasi-solid-state Li$\mathrm{O}_{2}$ batteries (Supplementary Figure 9d), suggesting that the graphene/Li anode in this quasi-solid-state $\mathrm{Li}-\mathrm{O}_{2}$ battery is not the determining factor for the cyclic performance.

The discharge products on the porous graphene cathode of the quasi-solid-state $\mathrm{Li}_{-} \mathrm{O}_{2}$ batteries were characterized by XRD and SEM. As shown in Fig. 3a, b, characteristic diffraction peaks corresponding to crystalline hexagonal $\mathrm{Li}_{2} \mathrm{O}_{2}$ are detected from a discharged cathode with a cutoff capacity of $5000 \mathrm{mAh} / \mathrm{g}$; these peaks disappear after subsequent recharge, implying the formation and complete decomposition of $\mathrm{Li}_{2} \mathrm{O}_{2}$. SEM reveals the formation of particulate $\mathrm{Li}_{2} \mathrm{O}_{2}$ with diameters of 300-500 nm uniformly distributed on the surfaces and inner pores of the porous graphene cathode (Fig. 3c). With the assistance of TTF, the $\mathrm{Li}_{2} \mathrm{O}_{2}$ particles can be completely decomposed at the low charging overpotential, as evidenced by the clean surface of the recharged porous graphene cathode (Fig. 3d). All these results verify that the reactions in the quasi-solid-state $\mathrm{Li}-\mathrm{O}_{2}$ battery follow the typical $\mathrm{Li}-\mathrm{O}_{2}$ electrochemistry of $2 \mathrm{Li}+\mathrm{O}_{2} \rightleftharpoons \mathrm{Li}_{2} \mathrm{O}_{2}$ and permit the highly reversible $\mathrm{Li}_{2} \mathrm{O}_{2}$ formation and decomposition. For the graphene/Li anodes, the 3D porous structure and the uniform Li coating are well maintained except that the surface becomes slightly rough (Supplementary Figure 10a). No Li dendrites are observed, suggesting the formation of robust and uniform solid electrolyte interphase (SEI) films on the Li surfaces. XPS reveals that the SEI layer is mainly composed of the decomposition products of DMSO and PVDF-HFP, including $\mathrm{Li}_{2} \mathrm{SO}_{4}, \mathrm{Li}_{2} \mathrm{~S}, \mathrm{Li}_{2} \mathrm{O}, \mathrm{LiF}$, and some organic $\mathrm{Li}$ species (Supplementary Figure 10b-f).

\section{Graphene-based quasi-solid-state $\mathrm{Li}-\mathrm{O}_{2}$ pouch batteries}

To explore the capability of the graphene-based quasi-solid-state $\mathrm{Li}-\mathrm{O}_{2}$ batteries for practical applications, we scaled up the coin battery to a large pouch- 


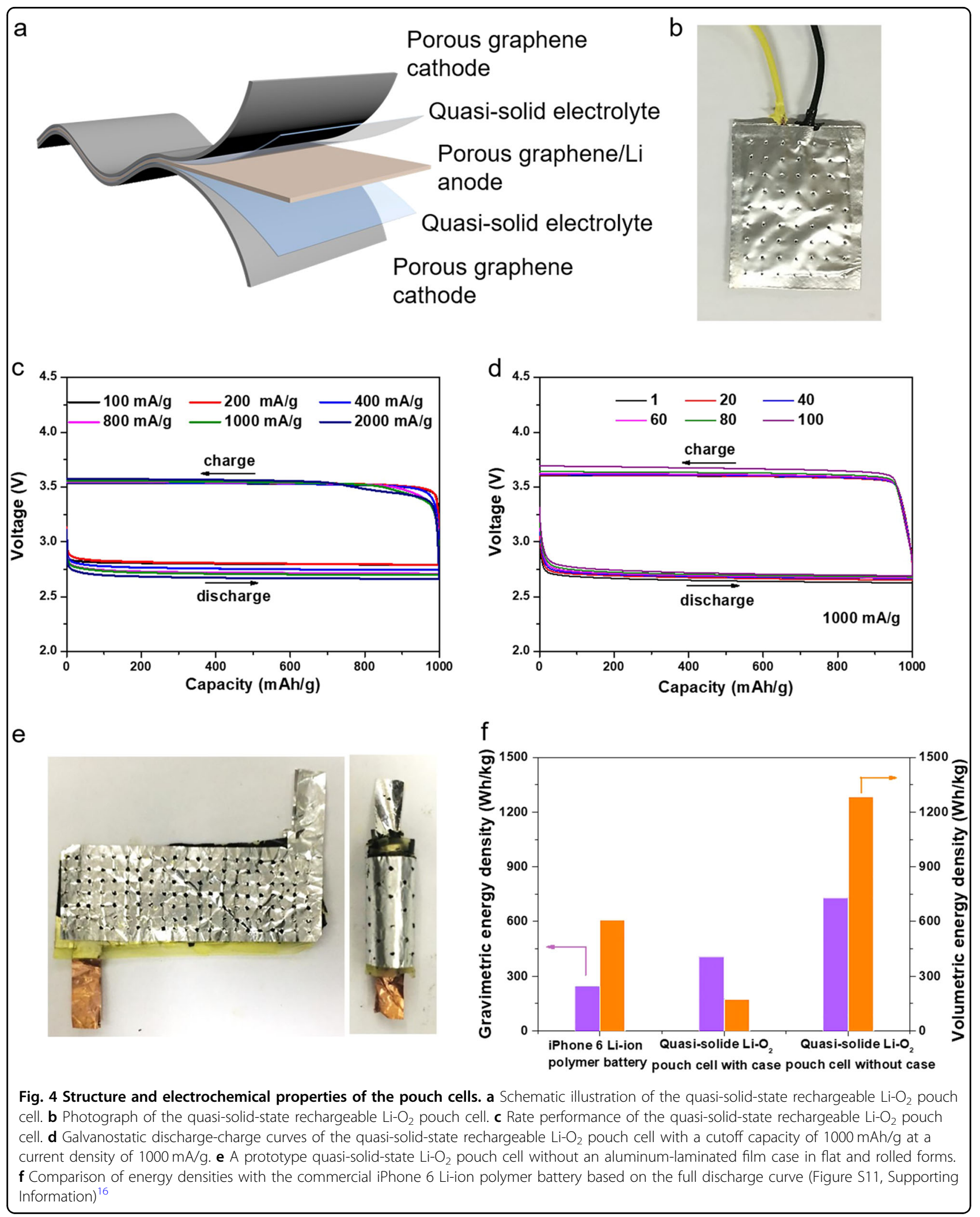


type cell with a size of $26 \mathrm{~mm} \times 38 \mathrm{~mm} \times 1.2 \mathrm{~mm}$. As schematically illustrated in Fig. $4 \mathrm{a}$, the quasi-solidstate $\mathrm{Li}-\mathrm{O}_{2}$ pouch cell is assembled by laminating one piece of porous graphene/Li sheet as the anode, two pieces of GPE-TTF as the electrolyte and separators, and two pieces of porous graphene sheets as the cathodes, which are then sealed inside an aluminumlaminated film case with pinholes on both sides. Fig. 4b is a photograph of a prototype pouch-type cell. The cell is mechanically flexible and can be scrolled without degeneration in battery performance (Supplementary Figure 11a). Excellent rate performance has been achieved for the quasi-solid-state $\mathrm{Li}-\mathrm{O}_{2}$ pouch cell. As shown in Fig. 4c, with the increase in current density from 100 to $2000 \mathrm{~mA} / \mathrm{g}$, the charge voltage plateau exhibits good reproducibility, and the discharge voltage plateau experiences a gentle and insignificant decrease. Cycling tests of the $\mathrm{Li}-\mathrm{O}_{2}$ pouch cell demonstrate a high durability with stable cycling up to 100 cycles at a cutoff capacity of $1000 \mathrm{mAh} / \mathrm{g}$ and a current density of $1000 \mathrm{~mA} / \mathrm{g}$ (Fig. 4d). Apparently, the excellent performance that was achieved with coin cells can be completely reproduced by large-sized pouch batteries. Importantly, a full discharge capacity up to $33230 \mathrm{mAh} / \mathrm{g}_{\text {cathode }}$ can be delivered when $70 \mu \mathrm{m}$ thick porous graphene is used as the pouch cell cathode (Supplementary Figure 11b, Tables 1 and 2). The gravimetric energy density and volumetric energy density of the pouch cell reach $408.48 \mathrm{Wh} / \mathrm{kg}_{\text {cell }}$ and $174.83 \mathrm{Wh} / \mathrm{L}_{\text {cell }}$, respectively, which are calculated based on the total mass and volume of the device (Supplementary Table 2). These values far exceed those of our recently reported liquid electrolyte-based $\mathrm{Li}-\mathrm{O}_{2}$ batteries $\left(260.30 \mathrm{Wh} / \mathrm{kg}_{\text {cell }}, 110.81 \mathrm{Wh} / \mathrm{L}_{\text {cell }}\right)^{16}$. If the pouch-type cell obviates the use of an aluminumlaminated film case (which accounts for a major proportion of the weight and volume in the cell), then the energy densities can reach $727.84 \mathrm{Wh} / \mathrm{kg}_{\text {cell }}$ without case and $1285.05 \mathrm{Wh} / \mathrm{L}_{\text {cell }}$ without case (Supplementary Table 2). These metrics that do not consider the packages are of practical significance since the case would not require the same lateral size as the main cell components for the large-scale integration of flexible quasi-solid-state $\mathrm{Li}-\mathrm{O}_{2}$ cells. A preliminary prototype for such a cell is shown in Fig. 4e. The cell laminates were rolled into a rod shape, saving a large volume of package materials. Figure 4f compares the energy densities of the graphene-based quasi-solid-state $\mathrm{Li}-\mathrm{O}_{2}$ pouch cell with those of a commercial Li-ion polymer battery, highlighting the gravimetric energy-density advantage of our quasi-solid-state $\mathrm{Li}-\mathrm{O}_{2}$ pouch batteries. Furthermore, the volumetric energy density calculated without packaging fixation materials far exceeds the value for commercial Li-ion polymer batteries, demonstrating an appealing design for boosting the volumetric energy density of $\mathrm{Li}-\mathrm{O}_{2}$ batteries.

\section{Discussion}

The outstanding battery performance achieved in both the coin-type and pouch-type quasi-solid-state $\mathrm{Li}-\mathrm{O}_{2}$ batteries originates from the unique structural features of the porous graphene cathode, the GPE-TTF, and the graphene/Li anode as well as their synergistic effects in the integrated cells. First, the nanoporous graphene cathode, with its high surface area and large porosity, offers a high density of active sites for $\mathrm{O}_{2}$ reduction and TTF oxidation and plentiful channels facilitating $\mathrm{O}_{2}, \mathrm{Li}^{+}$, and TTF transport. Second, GPE-TTF affords low $\mathrm{Li}^{+}$ion diffusion resistance, relieves shuttle reactions between the TTF and the graphene/Li anode, and suppresses electrolyte volatilization and $\mathrm{Li}$ dendrite formation. In addition, TTF can mediate $\mathrm{Li}_{2} \mathrm{O}_{2}$ oxidation at a low overpotential, alleviate the decomposition of GPE, and suppress side reactions. Third, the porous graphene/Li anode simultaneously solves the dendrite growth and infinite volume change issues of the metal $\mathrm{Li}$ anode. Therefore, all three components are indispensable and vitally important to guarantee the excellent electrochemical performance of quasi-solid-state $\mathrm{Li}-\mathrm{O}_{2}$ batteries.

In summary, we have developed a full-performance quasi-solid-state $\mathrm{Li}-\mathrm{O}_{2}$ battery consisting of a rationally designed porous graphene cathode, TTF-modified GPE, and porous graphene/Li anode. The issues of high charge overpotential, instability of liquid electrolytes, and dendrite growth and pulverization of metal $\mathrm{Li}$ anodes can be efficiently resolved in the integrated battery. As a result, outstanding battery performance in terms of round-trip efficiency, cycling stability, and rate capability have been realized in both coin-type and large-scale pouch-type batteries. In particular, the pouch batteries deliver high gravimetric energy density and volumetric energy density that exceed those of the commercial Li-ion polymer battery. This study paves a new avenue for designing and fabricating safe and stable $\mathrm{Li}-\mathrm{O}_{2}$ batteries with full performance and represents important progress for the practical implementation of high-energy $\mathrm{Li}_{-} \mathrm{O}_{2}$ batteries.

\section{Acknowledgements}

This work was sponsored by JST-CREST "Phase Interface Science for Highly Efficient Energy Utilization", JST (Japan); and Fusion Research Funds from WPIAIMR, Tohoku University.

\section{Author details}

${ }^{1}$ WPI Advanced Institute for Materials Research, Tohoku University, Sendai 9808577, Japan. ${ }^{2}$ Department of Materials Science and Engineering, Johns Hopkins University, Baltimore, MD 21214, USA. ${ }^{3}$ CREST, JST, 4-1-8 Honcho Kawaguchi Saitama, 332-0012 Kawaguchi, Japan 


\section{Author contributions}

M.C. conceived and supervised the research project. G.H. and J.H. prepared the samples and conducted the electrochemical measurements. C.Y. and Z.W. contributed to the SEM data analysis. G.H., J.H., and M.C. wrote the paper. All the authors discussed the results and reviewed the paper.

\section{Conflict of interest}

The authors declare that they have no conflict of interest.

\section{Publisher's note}

Springer Nature remains neutral with regard to jurisdictional claims in published maps and institutional affiliations.

Supplementary information is available for this paper at https://doi.org/ 10.1038/s41427-018-0095-5.

Received: 21 February 2018 Revised: 11 June 2018 Accepted: 23 July 2018. Published online: 7 November 2018

\section{References}

1. Bruce, P. G., Freunberger, S. A., Hardwick, L. J. \& Tarascon, J. M. Li-O 2 and Li-S batteries with high energy storage. Nat. Mater. 11, 19-29 (2012).

2. Luntz, A. C. \& McCloskey, B. D. Nonaqueous Li-air batteries: a status report. Chem. Rev. 114, 11721-11750 (2014).

3. Liu, Q. C., Xu, J. J., Xu, D. \& Zhang, X. B. Flexible lithium-oxygen battery based on a recoverable cathode. Nat. Commun. 6, 7892 (2015).

4. Aurbach, D., McCloskey, B. D., Nazar, L. F. \& Bruce, P. G. Advances in understanding mechanisms underpinning lithium-air batteries. Nat. Energy 1, 16128 (2016).

5. Gao, X. W., Chen, Y. H., Johnson, L. R., Jovanov, Z. P. \& Bruce, P. G. A rechargeable lithium-oxygen battery with dual mediators stabilizing the carbon cathode. Nat. Energy 2, 17118 (2017).

6. Wu, S. C. et al. Organic hydrogen peroxide-driven low charge potentials for high-performance lithium-oxygen batteries with carbon cathodes. Nat Commun. 8, 15607 (2017).

7. Thotiyl, M. M. O., Freunberger, S. A., Peng, Z. \& Bruce, P. G. The carbon electrode in nonaqueous $\mathrm{Li}-\mathrm{O}_{2}$ cells. J. Am. Chem. Soc. 135, 494-500 (2013).

8. Chang, Z. W., Xu, J. J., Liu, Q. C., Li, L. \& Zhang, X. B. Recent progress on stability enhancement for cathode in rechargeable non-aqueous lithium-oxygen battery. Adv. Energy Mater. 5, 1500633 (2015).

9. Li, Y., Wang, X. G., Dong, S. M., Chen, X. \& Cui, G. L. Recent advances in nonaqueous electrolyte for rechargeable Li-o2batteries. Adv. Energy Mater. 18, 1600751 (2016)

10. Li, F. J., Zhang, T. \& Zhou, H. S. Challenges of non-aqueous $\mathrm{Li}-\mathrm{O}_{2}$ batteries: electrolytes, catalysts, and anodes. Energy Environ. Sci. 6, 1125-1141 (2013).

11. Lin, D. C., Liu, Y. Y. \& Cui, Y. Reviving the lithium metal anode for high-energy batteries. Nat. Nanotech. 12, 194-206 (2017).

12. Gerbig, O., Merkle, R. \& Maier, J. Electron and ion transport in $\mathrm{Li}_{2} \mathrm{O}_{2}$. Adv. Mater. 25, 3129-3133 (2013).
13. Choudhury, S. et al. Designer interphases for the lithium-oxygen electrochemical cell. Sci. Adv. 3, e1602809 (2017).

14. Xiao, J. et al. Hierarchically porous graphene as a lithium-air battery electrode. Nano. Lett. 11, 5071-5078 (2011)

15. Lu, J. et al. A nanostructured cathode architecture for low charge overpotential in lithium-oxygen batteries. Nat. Commun. 4, 2383 (2013).

16. Han, J. H. et al. Full performance nanoporous graphene based $\mathrm{Li}-\mathrm{O}_{2}$ batteries through solution phase oxygen reduction and redox-additive mediated $\mathrm{Li}_{2} \mathrm{O}_{2}$ oxidation. Adv. Energy Mater. 7, 1601933 (2017).

17. Chen, Y., Freunberger, S. A., Peng, Z., Fontaine, O. \& Bruce, P. G. Charging a $\mathrm{Li}-\mathrm{O}_{2}$ battery using a redox mediator. Nat. Chem. 5, 489-494 (2013).

18. Lim, H. D. et al. Superior rechargeability and efficiency of lithium-oxygen batteries: hierarchical air electrode architecture combined with a soluble catalyst. Angew. Chem. Int. Ed. 53, 3926-3931 (2014).

19. Liang, Z. \& Lu, Y. C. Critical role of redox mediator in suppressing charging instabilities of lithium-oxygen batteries. J. Am. Chem. Soc. 138, 7574-7583 (2016).

20. Wu, F. et al. Platinum-coated hollow graphene nanocages as cathode used in lithium-oxygen batteries. Adv. Funct. Mater. 26, 7626-7633 (2016).

21. Han, J. et al. Effect of chemical doping on cathodic performance of bicontinuous nanoporous graphene for $\mathrm{Li}_{-} \mathrm{O}_{2}$ batteries. Adv. Energy Mater. 6 1501870 (2016)

22. Ito, Y. et al. Multifunctional porous graphene for high-efficiency steam generation by heat localization. Adv. Mater. 27, 4302-4307 (2015).

23. Guo, X. et al. 3D nanoporous nitrogen-doped graphene with encapsulated $\mathrm{RuO}_{2}$ nanoparticles for $\mathrm{Li}_{-} \mathrm{O}_{2}$ batteries. Adv. Mater. 27, 6137-6143 (2015).

24. Yang, C. P., Yin, Y. X., Zhang, S. F., Li, N. W. \& Guo, Y. G. Accommodating lithium into 3D current collectors with a submicron skeleton towards long-life lithium metal anodes. Nat. Commun. 6, 8058 (2015)

25. Lin, D. C. et al. Layered reduced graphene oxide with nanoscale interlayer gaps as a stable host for lithium metal anodes. Nat. Nanotech. 11, 626-632 (2016).

26. $\mathrm{Ye}, \mathrm{H}$. et al. Stable Li plating/stripping electrochemistry realized by a hybrid Li reservoir in spherical carbon granules with $3 \mathrm{D}$ conducting skeletons. J. Am. Chem. Soc. 139, 5916-5922 (2017).

27. Guo, Z. Y., Li, C., Liu, J. Y., Wang, Y. G. \& Xia, Y. Y. A long-life lithium-air battery in ambient air with a polymer electrolyte containing a redox mediator. Angew. Chem. Int. Ed. 56, 7505-7509 (2017).

28. Yang, X. Y. et al. High-performance integrated self-package flexible $\mathrm{Li}_{-} \mathrm{O}_{2}$ battery based on stable composite anode and flexible gas diffusion layer. Adv. Mater. 29, 1700378 (2017).

29. Liu, Q. C. et al. A flexible and wearable lithium-oxygen battery with record energy density achieved by the interlaced architecture inspired by bamboo slips. Adv. Mater. 28, 8413-8418 (2016).

30. Ito, $\mathrm{Y}$. et al. Bicontinuous nanoporous $\mathrm{N}$-doped graphene for the oxygen reduction reaction. Adv. Mater. 26, 4145-4150 (2014).

31. $\mathrm{Hu}, \mathrm{X}$. F. et al. Quasi-solid state rechargeable $\mathrm{Na}-\mathrm{CO}_{2}$ batteries with reduced graphene oxide Na anodes. Sci. Adv. 3, e1602396 (2017). 